Marquette University

e-Publications@Marquette

Fall 1997

\title{
The Effects of Nutrition Package Claims, Nutrition Facts Panels, and Motivation to Process Nutrition Information on Consumer Product Evaluations
}

\author{
Scott B. Keller \\ University of Arkansas - Main Campus \\ Mike Landry \\ University of Arkansas - Main Campus \\ Jeanne Olson \\ University of Arkansas - Main Campus \\ Anne M. Velliquette \\ University of Arkansas - Main Campus \\ Scot Burton \\ University of Arkansas - Main Campus
}

See next page for additional authors

Follow this and additional works at: https://epublications.marquette.edu/market_fac

Part of the Marketing Commons

\section{Recommended Citation}

Keller, Scott B.; Landry, Mike; Olson, Jeanne; Velliquette, Anne M.; Burton, Scot; and Andrews, J. Craig, "The Effects of Nutrition Package Claims, Nutrition Facts Panels, and Motivation to Process Nutrition Information on Consumer Product Evaluations" (1997). Marketing Faculty Research and Publications. 71. https://epublications.marquette.edu/market_fac/71 


\section{Authors}

Scott B. Keller, Mike Landry, Jeanne Olson, Anne M. Velliquette, Scot Burton, and J. Craig Andrews

This article is available at e-Publications@Marquette: https://epublications.marquette.edu/market_fac/71 


\title{
The Effects of Nutrition Package Claims, Nutrition Facts Panels, and Motivation to Process Nutrition Information on Consumer Product Evaluations
}

\author{
Scott B. Keller, Mike Landry, Jeanne Olson, Anne \\ M. Velliquette, Scot Burton, and J. Craig Andrews
}

\begin{abstract}
In a laboratory experiment using a between-subjects design, the authors examine the effects on nutrition and product evaluations of nutrition claims made (e.g., "99\% fat free;" "low in calories") on a product package, product nutrition value levels, and enduring motivation to process nutrition information. Enduring motivation is shown to moderate the effects of product nutrition value on consumer evaluations. Also, nutrition claims interact with product nutrition value in affecting consumer perceptions of manufacturer credibility. Given the availability of nutrient levels in the Nutrition Facts panel on the back of the mock package, nutrition claims on the front of the package generally did not affect positively consumers' overall product and purchase intention evaluations. The authors discuss some implications of these findings, suggestions for further research, and study limitations. ${ }^{l}$
\end{abstract}

$\mathbf{R}$ egulations stemming from the Nutrition Labeling and Education Act (NLEA) of 1990 have resulted in major changes in nutrition information on food packages. Specifically, recent Food and Drug Administration (FDA)/U.S. Department of Agriculture (USDA) regulations resulting from the NLEA have produced standardized Nutrition Facts panels, as well as specific stipulations regarding use of nutrient content claims on packages (Food and Drug Administration 1993). Given these important changes, we examine effects of nutrition claims on the front of packages, nutrition value information presented in the Nutrition Facts panel, and consumers' motivation to process nutrition information on consumers' product-related judgments in a between-subjects experiment.

Although some exceptions exist, Nutrition Facts panels have been included on most food products since August, 1994, and are required to be of uniform design, typographic style, color scheme, and standard placement of information. The Nutrition Facts panel lists serving size and servings per container, plus total calories and calories from fat. Also

\footnotetext{
'The generalizability of the findings from this laboratory study may be restricted because the mock package used as the stimulus was examined outside of an actual in-store purchase environment. Because consumers in store settings may spend less time and care examining Nutrition Facts panels and are subject to a variety of other influences (Cole and Balasubramanian 1992), findings from this study may not generalize to such settings.

Scott Keller, Mike Landry, Jeanne Olson, and Anne VelliQUETTE (listed alphabetically to indicate equal contributions) are doctoral students, and SCOT BURTON is a professor, Department of Marketing and Transportation, University of Arkansas. J. CRAIG ANDREws is a professor, Department of Marketing, Marquette University. The authors express their sincere appreciation to the editor and four anonymous reviewers for their many helpful comments and suggestions.
}

listed are amounts per serving and the percentage of daily values (DV) of total fat, saturated fat, cholesterol, sodium, total carbohydrates, dietary fiber, Vitamins A and C, calcium, and iron, based on a 2000-calorie daily diet (Food and Drug Administration 1993).

Food labeling regulations also indicate which specific nutrient claims can be made on packages and under what specific conditions these claims can be made. For example, the term "low in fat" requires that the product have three grams of fat or less (per 100 grams of food content for a meal/main dish) and 30\% or fewer calories from fat. Other claims, such as "99\% fat free" and "low in calories" (i.e., 120 calories or fewer per 100 grams of food content for a meal/main dish), also are regulated according to actual food content (Food and Drug Administration 1993, 2415-19).

\section{Research Objectives}

Various parties interested in nutrition, such as federal agencies, citizen groups, and marketers, have sought to evaluate the effects of the NLEA-based food labeling regulations (cf. Levy 1995; Moorman 1996). Some researchers, food marketers, and policymakers are positive about the effects of the NLEA; others, however, are more skeptical (e.g., see discussion among Pappalardo 1996; Petruccelli 1996; Silverglade 1996). Some have challenged claims that the goals of the NLEA have been accomplished and questioned whether the benefits have exceeded the $\$ 2$ billion it cost the food industry to implement labeling changes (e.g., Petruccelli 1996).

A primary objective of the NLEA was to create an information environment on packages to reduce consumer confusion (Pappalardo 1996; Petruccelli 1996) and "assist consumers in maintaining healthy dietary practices" (Nutrition Labeling and Education Act 1990). The present study addresses effects associated with nutrition claims on the front of packages and the nutrient data in the Nutrition Facts 
panels, both of which are key package changes resulting from the recent FDA/USDA food regulations.

In this context, we address three primary questions. The first regards nutrition claims currently allowed on food packaging (e.g., "99\% fat free," "low in calories"). Specifically, we test three nutrition claims across different levels of product nutrition and include a control condition in which no claim is made. We examine how these nutrition claims affect conclusions consumers draw about the product when the claims are consistent with the product's nutritional level shown in the Nutrition Facts panel and when they are not. Our second question regards the consumer's level of motivation to acquire and/or process nutrition information. Does such motivation moderate the effects of nutrition value level and/or package claims on nutrition and product evaluations? Our third question is whether consumers overlook nutrient information in the Nutrition Facts panel, which has important long-term health ramifications (e.g., information about sodium and cholesterol) because consumers focus more selectively on information on fat and saturated fat (Food Marketing Institute 1995, 1996; Ono 1995).

Here, we offer a partial replication of the recent research of Ford and colleagues (1996) that examines the relationship between claims and nutrition value information across levels of information ambiguity. Our research seeks to extend their work by examining (1) the role of motivation to process nutrition information as a postulated moderator based on both persuasion theory (Friestad and Wright 1994; Petty and Cacioppo 1986) and prior nutrition research (Moorman 1990), (2) the relative effects on primary household shoppers of several commonly used nutrient content claims (not examined previously) that are currently permitted by FDA/USDA regulations and the Nutrition Facts panels now required on most food products, and (3) consumer evaluations for products of which some nutrients that have been linked to heart disease are favorable (low fat and saturated fat), and others are unfavorable (high sodium and cholesterol). Thus, this study examines effects on consumers' nutrition and general product evaluations of package information based on FDA/USDA regulatory changes attempting to provide clear information that would assist consumers in their dietary decisions.

\section{Conceptual Rationale and Hypotheses}

\section{Nutrition Claims and Nutrition Value Levels}

Our study examines three promotional nutrition claims: "99\% fat free," "low in fat," and "low in calories." These claims are among those allowed by the FDA and emphasize nutrition-related concerns perceived as important to consumers (Burton and Biswas 1993; Heimbach and Stokes 1982). Given this high level of perceived importance to consumers, it is not surprising that such nutrition claims have been used by food manufacturers on packaging and other promotion material in attempts to influence positively consumer product perceptions and attitudes.

Conversely, one of the primary purposes of the NLEA is to make specific nutrition information on nutrition labels available in a clear and unambiguous format that would promote healthy dietary practices (Pappalardo 1996; Petruccelli 1996). The FDA conducted extensive research (Levy, Fein, and Schucker 1991, 1996), reviewed industry and academic research, and used the compilation of these findings as input to its design of the final label format to help ensure its usefulness to consumer decision making (Food and Drug Administration 1993).

When presented with package stimuli that include both a promotional nutrition claim made by the manufacturer and the standardized Nutrition Facts panel, consumers may use an information accessibility/diagnosticity framework. This enables consumers to determine the perceived relative importance of package stimuli and information retrieved from memory in making judgments or decisions about the product (Alba, Hutchinson, and Lynch 1991; Feldman and Lynch 1988). Accessibility is the ease with which a piece of information is retrieved from memory or obtained from the immediate environment. Diagnosticity is the perceived usefulness of the information in reaching a judgment or decision objective. With prominent positions on the package and size requirement specifications, both a promotional nutrition claim and the Nutrition Facts panel are highly accessible. Although claims may be slightly more accessible given their visibility on the front of a package, when such claims are made, they must specify the location of the Nutrition Facts panel (e.g., "See back panel for nutrition information").

Because the Nutrition Facts information is specific, standardized, and designed to be useful in dietary decisions, the information in the panel should be perceived as far more diagnostic than any manufacturer's claim and most memorybased information. Also, there has been a targeted promotional campaign for the Nutrition Facts label to increase consumer awareness and knowledge regarding the label and its informative mission (Burros 1994). Thus, consumers should view any promotional claim made on the package by the manufacturer as relatively nondiagnostic compared to the Nutrition Facts label. Given the diagnosticity of the information in the label, consumers seem unlikely to make evaluative judgments solely on the basis of claims made on the front of the package and may question the credibility of manufacturers making claims not consistent with the label information.

Such suspicion regarding claims is consistent with "schemer schemas" (i.e., consumers' general theories regarding the persuasive intentions of marketers) and the persuasion knowledge model (Friestad and Wright 1994; Wright 1986). These concepts suggest that consumers become aware of marketers' attempts to persuade (e.g., specific promotional tactics) and subsequently develop a base of knowledge about persuasion tactics used by marketers. This knowledge leads to coping behaviors that are used when persuasion attempts occur (Friestad and Wright 1994, p. 3). These coping mechanisms affect consumers' beliefs and attitudes associated with the persuasion attempt. For example, consumers may view a package claim (e.g., "low in fat") as a persuasive tactic to help sell the product. If other information from memory or on the label appears inconsistent with such a claim, the consumer may question the manufacturer's credibility, and product judgments should not be influenced positively by such claims. Consistent with the persuasion knowledge model, recent FDA focus group interviews indicate that consumers are highly skeptical of health and nutrition claims on packages because they view claims as attempts by the manufacturer to sell more of their product (Levy 1995). Adding to this suspicion was the fact 
that most focus group members were unaware of government regulations that specify when claims can be made. In contrast, many group members seemed confident about the information in the Nutrition Facts panel and said they would use it to verify front package claims (Levy 1995). Such findings appear similar to a two-step model of advertising that proposes that advertising claims lead to tentative hypotheses that are subsequently tested when more credible information (such as the Nutrition Facts panel) becomes available (Deighton 1984).

Ford and colleagues (1996) recently examined whether consumers' evaluations of product nutrition are affected by a health claim (e.g., "It does your heart good") when specific nutrition label information is present. In a $2 \times 2 \times 2$ experiment, they examined health claims on the front of the package (present or absent), nutrition value (favorable or unfavorable), and nutrition label ambiguity (one unambiguous and one ambiguous format). They found that overall product nutrition beliefs are not affected by the health claim and that the health claim does not interact with the back panel nutrition label. Specific study objectives caused claims and formats that Ford and colleagues (1996) used to differ somewhat from those specified in regulations stemming from the NLEA (Food and Drug Administration 1993). Nevertheless, their results suggest that consumers will not draw incorrect conclusions about overall nutrition and product evaluations from claims when specific nutrient information is readily available in Nutrition Facts labels. Given consumer suspicion of claims based on the persuasion knowledge model, plus previous FDA research (Levy 1995) and the presence of accessible diagnostic information in the Nutrition Facts label, nutrition claims should have little effect on consumer evaluation of nutrition. However, given some suspicion and consumer perception of these claims as a form of manufacturer promotion, claims not consistent with the label information should affect perceptions of manufacturer credibility.

$\mathrm{H}_{1}$ : Nutrition claims that are not consistent with nutrition value information (supplied in a Nutrition Facts panel) have a stronger negative effect on consumer evaluations of manufacturer credibility than claims that are consistent, or when no claim is used.

Justification for $\mathrm{H}_{1}$ suggests that the diagnostic information in the Nutrition Facts label should have a strong effect on consumer product evaluations relative to the claims. Besides this main effect of nutrition value, there is interest in the role of certain nutrients in affecting product evaluations. Because of the NLEA goal to assist consumers in maintaining healthy dietary choices, FDA regulations explicitly recognize the association of several targeted nutrients with long-term disease risk. For example, sodium and cholesterol have been linked to hypertension and heart disease, respectively, and fat has been linked to some types of cancer and heart disease.

Some recent survey findings suggest that consumers pay less attention to sodium and cholesterol levels and choose to concentrate on total fat grams or calories from fat (Food Marketing Institute 1992, 1996; Ono 1995). Sixty percent of consumers report fat content as their greatest nutritional concern, compared to only $25 \%$ who express concern over cholesterol and sodium (Food Marketing Institute 1996). Similarly, $56 \%$ of consumers report that the most useful information on the new labels is about fat, compared to $25 \%$ and $15 \%$ who mention salt and cholesterol, respectively (Food Marketing Institute 1996). Consumer reports of the nutrient information from Nutrition Facts labels that is responsible for stopping them from buying food products are more dramatic. Specifically, $72 \%$ say they stopped buying a product because of fat content compared to only $27 \%$ and $11 \%$ for sodium and cholesterol, respectively (Food Marketing Institute and Prevention Magazine 1995).

These survey results suggest that many people rely on Nutrition Facts information to avoid foods high in fat but set aside concerns about sodium and cholesterol levels. Because the NLEA regulations explicitly acknowledge that available scientific evidence links sodium and cholesterol to an increased risk of heart disease and/or conditions related to heart disease (Food and Drug Administration 1993; Liebman 1995), recognition of sodium and cholesterol levels is a concern for consumer welfare. For the nutrition value effect postulated in $\mathrm{H}_{2}$, it is anticipated that there will be little difference in evaluations for nutrition conditions that vary in levels of sodium and cholesterol but are equivalent in levels of fat and other nutrients. ${ }^{2}$

$\mathrm{H}_{2}$ : Higher levels of nutrition value (suggested in a Nutrition Facts panel in the context of total package information) result in a more favorable attitude toward the product, purchase intentions, and product nutrition attitude.

\section{The Role of Motivation to Process Nutrition Information}

The information accessibility/diagnosticity framework used previously as a basis for predictions presumes that all consumers obtain and process nutrition information in a similar manner. However, individual differences, such as the enduring motivation to process nutrition information, may affect consumers' perception, processing, and evaluation of information on specific claims and nutrient data offered on product packages (Petty and Cacioppo 1986). This motivation construct, defined as a disposition to attend to nutrition information that reflects goal-directed arousal (Moorman 1996), may affect perceptions of accessibility and diagnosticity (i.e., usefulness) of specific types of information in product evaluations. For example, consumers with lower enduring motivation to process may place greater emphasis on the most easily accessible information, such as a promotional claim made on the front of the package. They may not

\footnotetext{
2More specifically, this experiment examines "poor," "medium," and "good" levels of product nutrition value by manipulating levels of specific nutrients in the Nutrition Facts panel. There are relatively large differences between sodium and cholesterol levels between the "medium" and "good" conditions, but all other nutrition information in the labels remains the same for these two treatment levels. For the "poor" and "medium" conditions, there are large differences in levels of fat, saturated fat, calories from fat, and other nutrients, but sodium and cholesterol levels remain the same. Because of the recent literature pertaining to the lesser importance that consumers place on sodium and cholesterol information, it is anticipated that the contrast between the "medium" and "good" treatments will show little difference in means. However, it is expected that the differences in nutrients (including fat and calories from fat) between the "poor" and "medium" conditions will result in large, significant differences in nutrition and product evaluations. Other differences in nutrients (e.g., protein, fiber) between the "poor" and "medium" conditions make a strong test problematic for these two conditions, and therefore no specific hypothesis is offered.
} 
perceive the detailed information in the Nutrition Facts panel as necessary for the judgment task at hand. This suggests that the motivation construct will moderate the relative effects of nutrition value and nutrition claims, and claims may have a greater effect for less motivated consumers.

Empirical research pertaining to enduring motivation to process nutrition information shows mixed findings. Moorman (1990, p. 372) finds that enduring motivation is related significantly to one measure of ability to process but not to measures of comprehension accuracy or subjective or objective decision quality. In a recent study, motivation to process in the post-NLEA environment was shown to be related significantly to information acquisition, but there was little effect on a measure of information comprehension (Moorman 1996, p. 39). Interactions between motivation and time (pre-/postNLEA) were significant for the information acquisition ( $p<$ $.05)$ and information comprehension $(p<.10)$ measures.

Support for a moderating role of enduring motivation in the context of the present study also is offered by the elaboration likelihood model. When a consumer's motivational intensity is high, he or she will be more likely to engage in more effortful cognitive processing to evaluate information (Andrews and Shimp 1990; Petty and Cacioppo 1979; Petty, Unnava, and Strathman 1991). More motivated consumers are willing to spend more time processing and elaborating on information viewed as central or most relevant to a judgment task (such as the specific and detailed information in the Nutrition Facts panel). Again, this suggests that enduring motivation to process nutrition information may moderate the relative effects of nutrition value levels (indicated by information in Nutrition Facts labels) and nutrition claims on the front of a package.

$\mathrm{H}_{3}$ : Consumers' levels of motivation to process moderate the effect of nutrition value on nutrition and product evaluations. For consumers with higher levels of motivation, nutrition and product evaluations are (1) more favorable for a product that is higher in nutrition value and (2) less favorable for a product that is lower in nutrition value than for consumers with lower levels of motivation.

$\mathrm{H}_{4}$ : Consumers' levels of motivation to process moderate the effects of nutrition claims on nutrition and product evaluations. Compared to packages on which no claims are made, packages with nutrition claims result in more favorable nutrition and product evaluations for consumers with lower motivation than for those with higher motivation.

\section{Method}

\section{Pretest}

To examine the hypotheses, we conducted a 4 (nutrition content claims such as " $99 \%$ fat free" and "low in calories") $\times 3$ (product nutrition value) $\times 2$ (consumer motivation to process nutrition information) between-subjects experiment. To determine the specific nutrition value levels to be used in the main study, a pretest was performed first. To enhance comparability with previous nutrition research (Burton, Biswas, and Netemeyer 1994; Ford et al. 1996), a frozen dinner with a chickenbased entree was employed in our pretest and main study. Pretest subjects were presented with one of two Nutrition Facts panels that varied in the nutrient levels provided. Subjects were presented with either a "good" or a "poor" nutrition value condition (see Appendix A), both of which were based on frozen chicken dinners actually on the market. Subjects rated the two labels on two seven-point scales assessing perceived product nutritiousness (e.g., "Do you consider the nutrition level offered by the product to be...?" with endpoints of "poor" and "good"). The overall summed mean for the "good" condition ( $M=10.15)$ was significantly greater than the "poor" condition $(\mathrm{M}=5.61 ; \mathrm{t}=5.93$, $\mathrm{df}=52, p<.001)$, and these evaluations fell on the desired sides of the summed scale midpoint.

\section{Sample and Procedure}

Respondents in the main study were members of a statewide household research panel. Approximately 800 members were randomly mailed one version of a mock package design and a survey that was invariant across the package conditions. The data were collected in August and September 1995, approximately one year after the NLEA-based regulations went into effect. The response rate was approximately $58 \%$. All respondents were the primary shoppers for their households; $73.5 \%$ were females, $26.5 \%$ males, and the median age was 46 years.

As was noted previously, the product stimulus was a frozen meal-based chicken dinner. Survey instructions indicated that the research pertained to "food product packages" and that the mock package contained information similar to that found on actual frozen dinner packages. Subjects were instructed to examine the information on the mock package and then answer questions in the survey. Items on the front of the package included a picture and brief description of the product (i.e., chicken tenderloins with pasta and vegetables in a delicious sauce), the nutrition claim and related instructions to "See back panel for nutrition information," net weight, price, a "microwaveable" label, and instructions to "Keep frozen." The back of the mock package showed product ingredients, the Nutrition Facts panel, preparation directions for both microwave and conventional ovens, and scanner code. Nutrition content claims were among those approved by NLEA regulations, and the Nutrition Facts panel followed the uniform NLEA format.

\section{Independent Variables}

Nutrition claim types included four conditions: "99\% fat free," "low in fat," "low in calories," and a control group in which no claim was used. Each of these claims currently is permitted, emphasizes nutrition concerns important to consumers, and is used frequently on packages by food product manufacturers (e.g., Food and Drug Administration 1993; Ippolito and Mathios 1993). Nutrition value conditions ("poor," "medium," and "good") were manipulated by altering the nutrient levels in the Nutrition Facts panel (see Appen$\operatorname{dix}$ A). As was noted previously, the "poor" and "good" values were taken directly from chicken-based frozen dinners on the market, and differences in their perceived nutrition value were supported by the pretest. The "good" nutrition value included relatively low levels of total fat grams (2 grams, $3 \%$ of the recommended DV), saturated fat grams (.5 grams, $3 \%$ DV), cholesterol (20 milligrams, 7\% DV), and sodium (410 milligrams, $17 \% \mathrm{DV})$. The "poor" nutrition value included higher levels of total fat (21 grams, 32\% DV), saturated fat (10 grams, $50 \% \mathrm{DV})$, cholesterol (102 milligrams, 34\% DV), and sodium (830 milligrams, 35\% DV). (Because nutrient levels 
were from actual products, other nutrient levels also varied to a lesser degree between these two nutrition conditions.) For the "poor" nutrition value condition, none of the nutrition claims was consistent with the nutrition information presented in the Nutrition Facts panel. However, each of the claims was consistent with the nutrition information in the "medium" and "good" nutrition value conditions shown in Appendix A.

Nutrient levels for the "medium" nutrition value level were identical to the "good" nutrition value condition with the exception of the cholesterol and sodium levels. In the "medium" condition, the sodium ( 830 milligrams, $35 \%$ DV) and cholesterol (102 milligrams, 34\% DV) levels were set at the level of the "poor" nutrition value condition. Differences between the "medium" and "good" conditions thus permitted an assessment of whether these higher levels of sodium and cholesterol were incorporated (or ignored) in overall evaluations, given identical and favorable levels of fat, saturated fat, calories, and other nutrients in both of these conditions. ${ }^{3}$

Motivation to process nutrition information was a measured rather than manipulated variable. Three seven-point scale items were used to assess motivation to process nutrition information (e.g., "In general, how interested are you in reading nutrition and health-related information at the grocery store?" with endpoints of "not interested" and "very interested") and were drawn from the work of Moorman (1990). Coefficient alpha for the three-item measure was .94. A median split of the sum of the three items was performed, and the measure was recoded to reflect a low or high level of enduring motivation.

\section{Measures of Dependent Variables}

The dependent variables included multi-item measures of overall attitude toward the nutritiousness of the product (nutrition attitude), credibility of the product marketer (credibility), overall attitude toward the product (product attitude), and purchase intentions (purchase). It was anticipated that nutrition attitudes and credibility would be affected by the nutrition claims and nutrition value more directly than the broader constructs of product attitude and intention, which would be affected by the product description, price, preparation time, product size, and other factors. To help prevent these more general product attitudes from being biased unrealistically by nutrition evaluations, the survey used a funneling approach in which the product attitude and intention measures were asked before the more specific measures (nutrition attitude).

Seven-point scales were used for each item, and negatively worded items were recoded so that higher scores always reflected higher construct values. For each multiitem measure, means were calculated (i.e., sum/number of items) and used in subsequent analyses. Items used and estimates of reliability for these dependent measures are reported in Appendix B. In addition to the dependent measures used directly in tests of hypotheses, evaluations of individual nutrients (e.g., fat, cholesterol, protein, fiber,

${ }^{3}$ In the original design, two levels of product price were used on the basis of a pretest. Initial analyses indicated that price had an effect on some of the consumer evaluation measures but did not interact with any of the other independent variables. On the recommendation of reviewers, analyses in the text are reported across the two levels of price to focus more directly on results relevant to the NLEA and public policy research. calories) were collected using a nine-point scale with endpoints of "very unfavorable" and "very favorable."

Confirmatory factor analyses using LISREL 8 were performed to assess the discriminant validity of the four multiitem measures used in tests of hypotheses. Three tests advocated in the literature were performed (Anderson and Gerbing 1988; Fornell and Larcker 1981). In all cases the chi-square value associated with the four factor model was significantly less than the chi-square associated with the three-factor model (in which the items for two measures were specified as loading on a single construct). In the confirmatory four-factor model, none of the confidence intervals around the maximum likelihood estimate of the phi correlations $(+/-2$ standard errors) contained a value of 1 . The average variance-extracted estimates also were all greater than the square of the phi correlation between any two constructs (Fornell and Larcker 1981). In addition, the lambdas associated with the items for each construct were significant $(p<.001)$, and variance-extracted estimates all exceeded the recommended level of .50.

\section{Results}

A MANOVA with follow-up univariate tests for the four dependent variables was used to examine proposed hypotheses. Means are shown in Table 1, and multivariate and univariate results are shown in Table 2.

\section{Effects Pertaining to Nutrition Claims on the Package}

$\mathrm{H}_{1}$ involves the effects of package claims on consumer evaluations across levels of nutrition value. $\mathrm{H}_{1}$ predicts that nutrition claims that are not consistent with nutrition value information have a stronger (negative) effect on evaluations of manufacturer credibility than claims that are consistent or when no claims are made. The significant multivariate interaction of claim and nutrition value $(\mathrm{F}=2.3, p<.01)$ shown in Table 2 is generally supportive of $\mathrm{H}_{1}$, and follow-up univariate tests show that this finding is attributable solely to the univariate interaction for the dependent variable of product manufacturer credibility $(\mathrm{F}=5.9, p<.01)$.

A plot of relevant means is shown in Figure 1. In the "poor" nutrition value condition, the claims about levels of fat and calories ("low in fat," "99\% fat free," "low in calories") are not consistent with the nutrition information and are not in accord with NLEA claim specifications (i.e., the Nutrition Facts panel in this condition shows that the product is not low in fat). In this "poor" nutrition value condition, contrasts between the control condition $(M=4.62)$ and the pooled claim conditions for the credibility variable $(\mathrm{M}=$ $3.40)$ are significantly different $(\mathrm{t}=4.0, p<.01)$ and thus support $H_{1}$. Subjects who received the frozen dinner that was nutritionally "poor" rated the manufacturer's credibility as significantly lower $(\mathrm{t}=6.5, p<.01)$ when the package had the " $99 \%$ fat free" claim than when there was no claim at all. Similarly, credibility for the " $99 \%$ fat free" claim was lower than the "low in fat" and "low in calories" claim conditions (t-values $=3.9$ and 5.0, respectively, $p<.01$ for each). Means for both the "low in fat" $(\mathrm{M}=3.78)$ and "low in calories" $(M=4.14)$ claims are lower than the control condition, but only the "low in fat" claim is significantly different from the control in the "poor" nutrition value condition ( $t$ values 


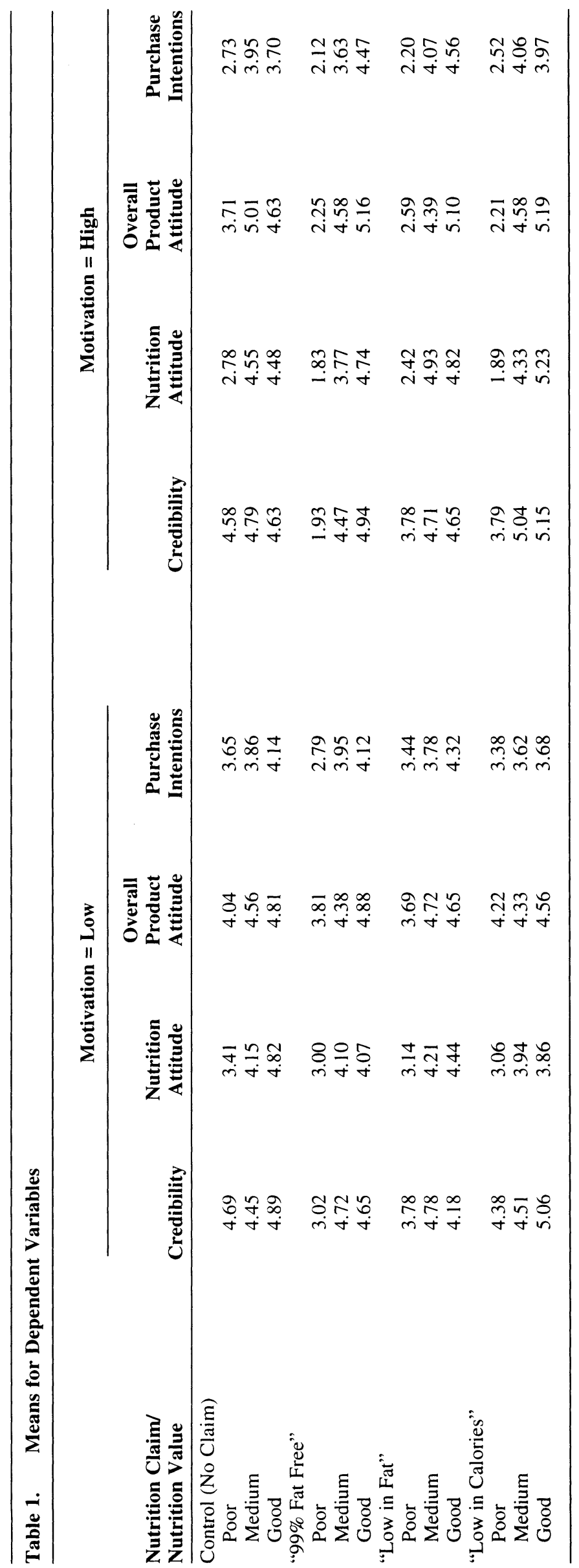


Table 2. Multivariate and Univariate Results

\begin{tabular}{|c|c|c|c|c|c|c|c|}
\hline \multirow[b]{2}{*}{$\begin{array}{l}\text { Independent } \\
\text { Variables }\end{array}$} & \multicolumn{3}{|c|}{ Manova Results } & \multicolumn{4}{|c|}{ Univariate F Values } \\
\hline & Wilks' $\Delta$ & F Value & df & $\begin{array}{c}\text { Nutrition } \\
\text { Attitude }\end{array}$ & Credibility & $\begin{array}{l}\text { Overall } \\
\text { Product } \\
\text { Attitude }\end{array}$ & $\begin{array}{l}\text { Purchase } \\
\text { Intention }\end{array}$ \\
\hline \multicolumn{8}{|l|}{ Main Effects } \\
\hline Nutrition Value $(\mathrm{N})$ & .75 & $16.6^{\mathrm{a}}$ & $(2,428)$ & $68.0^{\mathrm{a}}$ & $25.0^{\mathrm{a}}$ & $35.1^{\mathrm{a}}$ & $21.4^{\mathrm{a}}$ \\
\hline Claim (C) & .92 & $3.1^{\mathrm{a}}$ & $(3,428)$ & 2.4 & $7.0^{\mathrm{a}}$ & .7 & .4 \\
\hline Motivation (M) & .99 & .4 & $(1,428)$ & .1 & .2 & 2.8 & 1.9 \\
\hline \multicolumn{8}{|l|}{ Interaction Effects } \\
\hline $\mathrm{M} \times \mathrm{N}$ & .94 & $3.4^{a}$ & $(1,428)$ & $10.3^{a}$ & 2.3 & 9.3a & $4.3^{b}$ \\
\hline $\mathrm{C} \times \mathrm{N}$ & .88 & $2.3^{a}$ & $(6,428)$ & .4 & $5.9^{\mathrm{a}}$ & .8 & 1.0 \\
\hline $\mathrm{C} \times \mathrm{M}$ & .98 & .9 & $(3,428)$ & .7 & .6 & .3 & .2 \\
\hline $\mathrm{M} \times \mathrm{N} \times \mathrm{C}$ & .94 & 1.2 & $(6,428)$ & 1.4 & 1.1 & .9 & .3 \\
\hline
\end{tabular}

a $p<.01$.

$\mathrm{b} p<.025$.

\section{Figure 1. Effects of Nutrition Claims on Perceived Credibility Across Levels of Product Nutrition Value}

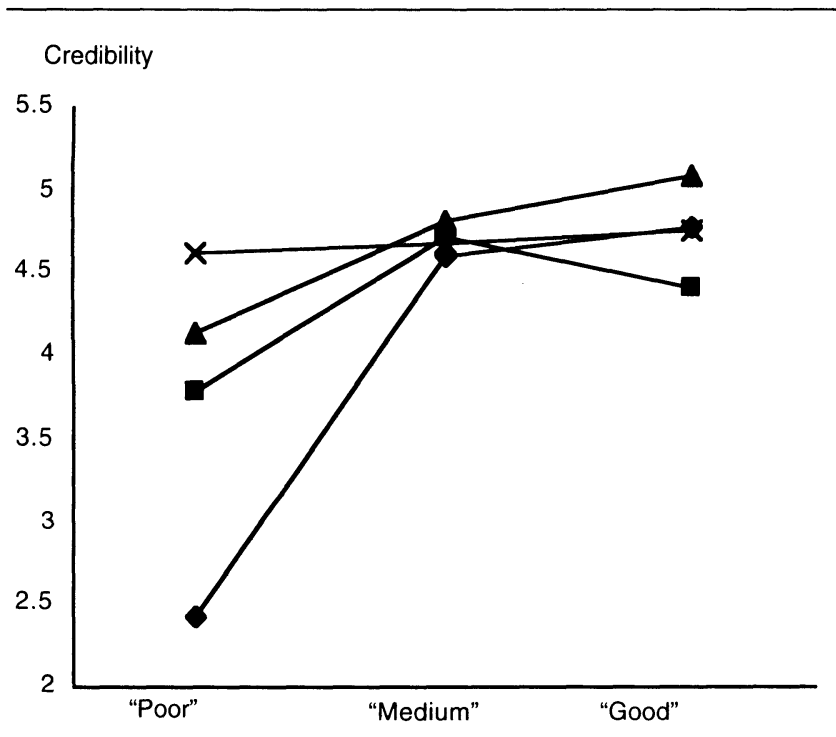

Nutrition Value

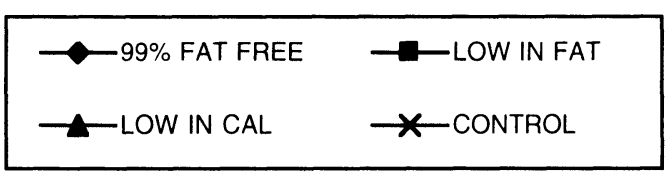

$=2.34, p<.025$ and 1.38 [ns], respectively). Despite this significant difference for the "low in fat" claim, its much higher score relative to that of the " $99 \%$ fat free" claim raises an interesting policy issue discussed subsequently.

The three nutrition claims are consistent with NLEA specifications for both the "medium" and "good" nutrition conditions, and the theoretical justification for $\mathrm{H}_{1}$ suggests little effect of claims in these conditions. A MANOVA was performed for the nutrition and product evaluation variables across levels of the independent variables for these two nutrition value levels. For these "medium" and "good" conditions, claims do not interact or have a significant main effect in any multivariate or univariate tests.

$\mathrm{H}_{2}$ involves the effects of higher levels of nutrition value on consumer evaluations in the context of total package information (e.g., claims, product description, price, ingredients, net weight). The multivariate and univariate results shown in Table 2 suggest a strong effect of nutrition value on the dependent variables; however, because of the interaction between motivation and nutrition value, $\mathrm{H}_{2}$ is discussed along with hypotheses addressed in the following section.

\section{Effects of Enduring Motivation to Process Nutrition Information}

$\mathrm{H}_{3}$ and $\mathrm{H}_{4}$ predict that consumers' motivation to process moderates the effects of nutrition value $\left(\mathrm{H}_{3}\right)$ and claims $\left(\mathrm{H}_{4}\right)$ on consumer evaluations. Consistent with $\mathrm{H}_{3}$, there is a significant multivariate interaction between motivation and nutrition value (Wilks' $\Lambda=.94 ; \mathrm{F}=3.4, p<.01$ ), and this interaction extends to all follow-up univariate tests $(p<.025$ for all dependent variables except credibility $[p<.10])$. Plots of means for these interactions show that motivation moderates the effect of nutrition value consistently for each of the four dependent variables. ${ }^{4}$ The pattern of results is shown in Figures 2 and 3 for three of the variables: nutrition attitude, overall attitude toward the product, and purchase

\footnotetext{
${ }^{4}$ As suggested by a reviewer, we also performed hierarchical regression analyses in which nutrition value (low/high) and nutrition claim (present/absent) were dummy coded $(0,1)$ and then entered on an initial step along with the quantitative measure of motivation. Results suggested that the interaction of motivation and nutrition value was significant after accounting for variance explained by main effects, and the motivation by claim interaction was not significant, consistent with results in Table 2.
} 


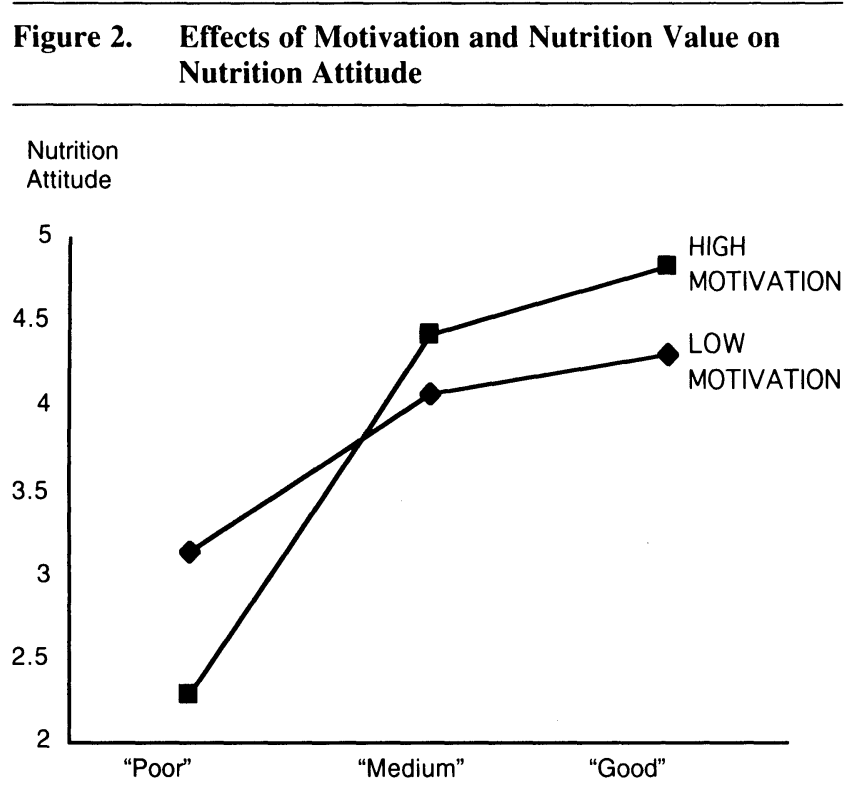

Nutrition Value

intentions. As shown in Figure 2, and consistent with $\mathrm{H}_{3}$, consumers with higher motivation have a more favorable nutrition attitude $(\mathrm{M}=4.82)$ than those with lower motivation $(\mathrm{M}=4.31 ; \mathrm{t}=2.14, p<.025)$ in the "good" nutrition condition. The pattern is reversed for the "poor" nutrition value condition. In this condition, the nutrition attitude of consumers with higher motivation $(M=2.28)$ is significantly lower $(\mathrm{t}=3.89, p<.01)$ than that of consumers with lower motivation $(\mathrm{M}=3.14) .5$

This supportive pattern of results extends beyond nutrition attitude to the more general constructs of product attitude and purchase intentions (shown in Figure 3), which are affected by a broader array of variables (e.g., price, promotion). For these dependent variables, in the "poor" nutrition value condition, there are significant differences in both product attitude $(\mathrm{t}=4.06, p<.01)$ and purchase intentions $(\mathrm{t}$ $=3.35, p<.01$ ) between the higher and lower levels of motivation. These higher evaluations of product attitudes and purchase intentions for the poor nutrition product for consumers lower in motivation have implications for consumer welfare that are addressed in the discussion section.

Although the means in the "good" value condition are slightly higher for consumers in the high motivation group, the differences in means are not statistically significant for either the product attitude or purchase intentions dependent variables ( $\mathrm{t}$ values $=1.17$ and 0.41 , respectively, $p>.10$ for both). This overall pattern of results indicates that differences in motivation levels lead to larger differences in consumers'

${ }^{5}$ Support for $\mathrm{H}_{3}$ also is demonstrated by the difference in attitudes between the "good" and "poor" nutrition value conditions across levels of motivation. Whereas the difference is significant for the low motivation group $(\mathrm{M}=1.17$ [i.e., $4.31-3.14$ ]; $\mathrm{t}=5.00, p<.01)$, the difference in attitude is much greater for the high motivation segment of consumers $(M=$ 2.54 [i.e., $4.82-2.28$ ]; $\mathrm{t}=10.4, p<.01$ ), and the $2 \times 2$ interaction involving the "good" and "poor" levels and motivation is significant $(F=17.6$ [1295], $p<.01)$.

\section{Figure 3. Effects of Motivation and Nutrition Value on Product Attitude and Purchase Intentions}
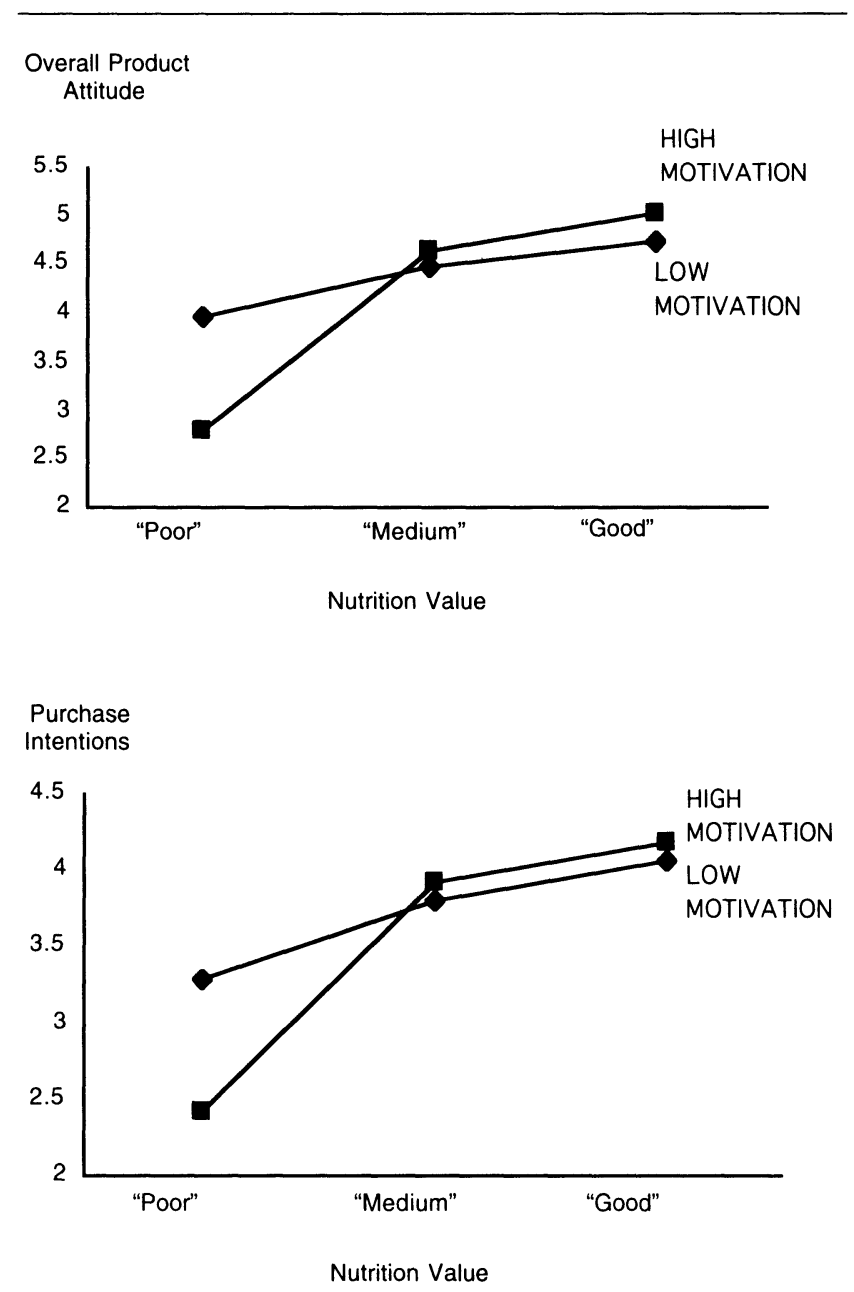

product and purchase attitudes for products lower in nutrition value than for those with more favorable levels of nutrition. Taken in sum, these findings support $\mathrm{H}_{3}$ predictions of motivation as a moderator of the effect of nutrition value on consumers' evaluations. Strong support is offered for products "poor" in nutrition value, and mixed support for the "good" value condition across the relevant dependent variables.

Because of the interaction between nutrition value and motivation, a direct test of the effects of nutrition value proposed in $\mathrm{H}_{2}$ is not possible, but plots in Figures 2 and 3 suggest an interpretable pattern of means. Although the slope of the plot of means differs across levels of motivation, as nutrition value improves, consumers' evaluations are higher for both motivation levels. For the high motivation group, univariate tests of the effect of nutrition value are significant for the dependent variables of nutrition attitude $(\mathrm{F}=63.5, p$ $<.01)$, product attitude $(\mathrm{F}=36.1, p<.01)$, and purchase intentions $(\mathrm{F}=21.8, p<.01)$. For the low motivation group, F values are $14.0(p<.01), 4.4(p<.05)$, and $4.2(p<.05)$, for nutrition attitude, product attitude, and purchase intentions, respectively. Thus, for consumers both lower and higher in motivation level, findings offer support for $\mathrm{H}_{2}$.

We expected that consumers would perceive little difference between the "medium" and "good" nutrition condi- 
tions, which differed in their levels of cholesterol and sodium but were identical in terms of fat and all other nutrient levels. Plots of the means for the "medium" and "good" nutrition value levels shown in Figures 2 and 3 are relevant to this question. For the higher motivation group, nutrition attitude is slightly higher for the "good" condition $(\mathrm{M}=$ $4.82)$ than for the "medium" condition $(\mathrm{M}=4.42 ; \mathrm{t}=1.69$, $p<.05)$. For those lower in motivation, the difference between the "good" condition $(\mathrm{M}=4.31)$ and the "medium" condition $(\mathrm{M}=4.09)$ is not significant $(\mathrm{t}=0.92, p>.10)$. This general pattern of results is similar for overall product attitude and purchase intentions, but for both the higher and lower motivation groups the difference between the "medium" and "good" conditions is nonsignificant. These findings suggest that the nutrition and product-related attitudes of all consumers are not influenced greatly by information on cholesterol and sodium. Also, the higher motivation group appears more sensitive to the differences in cholesterol and sodium in their nutrition attitude evaluations than the less motivated consumers. For both high and low motivation groups, follow-up contrasts show significant differences between the "medium" and "poor" nutrition value levels across all dependent variables. 6

$\mathrm{H}_{4}$ postulates that there is an interaction between motivation and use of nutrition claims. We proposed that because consumers who were lower in motivation would be less likely to process the specific, detailed information in the Nutrition Facts panel, the noticeable and accessible claim on the front of the package would have a stronger effect on product evaluations for these less motivated consumers. However, the predicted multivariate interaction and followup univariate interactions shown in Table 2 are all nonsignificant. These results are also nonsignificant when the control condition is compared to the pooled results for the three favorable claims and for findings across all levels of nutrition value. Thus, $\mathrm{H}_{4}$ is not supported by these data. ${ }^{7,8}$

\section{Results Pertaining to Specific Nutrients}

In addition to the multi-item dependent variables addressed in prior analyses, ratings of specific nutrients also were collected because of their relevance to our research questions. Ratings of calories, sodium, cholesterol, fat, and calories from fat content were obtained using nine-point scales with endpoints of "very unfavorable" and "very favorable," and, as in previous analyses, these ratings were used as dependent variables in a MANOVA. Effects for these nutrients were similar to those for the multi-item attitudinal variables. All multivariate interactions were nonsignificant except for the motivation to process by nutrition value interaction (Wilks' $\Lambda=.93 ; \mathrm{F}=2.8, p<.025$ ). Univariate analyses for this interaction were significant for the amount of fat and calories from fat $(\mathrm{F}=11.9$ and 10.0 , respectively, $p<.01)$ and calories $(\mathrm{F}=4.0, p<.05)$. Plots show disordinal interactions similar to those in Figures 2 and 3. The multivariate main and interaction effects for nutrition claim were nonsignificant, and there was no evidence that the front package claims about fat had a positive effect on evaluation of fat levels compared to the control condition. (Tables and plots of means for these specific nutrient results are available on request from the first author.)

These ratings data for cholesterol and sodium also are relevant to questions of whether differences shown in the Nutrition Facts panel are recognized for these nutritional elements. As shown in Appendix A, in the "poor" and "medium" nutrition value conditions, cholesterol and sodium levels were equal (whereas other nutrients differed) but less favorable than in the "good" condition. All interactions involving nutrition value are nonsignificant for subjects' ratings of cholesterol and sodium. As would be expected, the multivariate main effect of nutrition value is strong and significant (Wilks' $\Lambda=.55 ; \mathrm{F}=$ 28.7), and univariate follow-ups for cholesterol and sodium are both significant $(\mathrm{F}=43.0$ and 10.0 , respectively, $p<.01)$.

For cholesterol, follow-up contrasts show that differences are significant between both the "poor" $(\mathrm{M}=2.67)$ and "medium" $(\mathrm{M}=3.45)$ nutrition value conditions $(\mathrm{t}=3.4, p$ $<.01)$ and the "medium" and "good" $(\mathrm{M}=4.62)$ conditions $(\mathrm{t}=5.0, p<.01)$. For sodium, differences between the "poor" $(\mathrm{M}=2.67)$ and "medium" $(\mathrm{M}=3.09)$ conditions are marginally significant $(\mathrm{t}=1.8, p<.10)$, and there are significant differences between the "medium" and "good" (M $=3.74)$ conditions $(\mathrm{t}=2.8, p<.01)$. Findings for the "poor" and "medium" conditions suggest that evaluations of cholesterol and sodium are not made necessarily in isolation and may be affected partially by evaluations of other nutri-
"Although differences between the "medium" and "good" conditions were of primary concern, there was also some interest in assessing the role of fat in differences between the "poor" and "medium" conditions. Because the nutrition information was based on actual frozen dinner products on the market, there are differences between nutrition conditions for nutrients other than fat, cholesterol, and sodium. In the "poor" and "medium" levels there are differences in calories, protein, vitamins/minerals, and fiber in addition to differences in fat-related nutrients. To control for these differences of other nutrients, analyses were performed in which subjects' ratings of nutrients other than fat were included as covariates. Differences between the "poor" and "medium" levels remained significant for all variables. When these same covariates were included, there were no significant differences between the "medium" and "good" conditions for any of the dependent variables.

${ }^{7}$ Given this pattern of results for motivation in $\mathrm{H}_{3}$ and $\mathrm{H}_{4}$, we examined differences across motivation for two items included at the end of the survey that were collected to help clarify the importance of front versus back panel information on product evaluations. In determining their evaluations, these two respective seven-point items asked the subjects how much attention they paid to information on (1) the front panel of the mock package and (2) the Nutrition Facts panel on the back of the package. For those high in motivation, the Nutrition Facts mean $(M=6.2)$ was greater than the mean for the front panel information $(\mathrm{M}=4.2 ; \mathrm{t}=12.1, p<.01)$. However, the Nutrition Facts panel mean (4.6) also was higher than the front panel mean (3.9) for those low in motivation $(t=4.0, p<.01)$. In addition, there were marked differences between the means for the Nutrition Facts panel for those high $(\mathrm{M}=6.2)$ and low in motivation $(\mathrm{M}=4.6 ; \mathrm{t}=10.1, p<.01)$, and the difference across motivation levels for the front of the package information was nonsignificant $(t=1.6, p>.10)$. This pattern of means appears highly consistent with our results that show significant motivation by nutrition value interactions but no interaction between motivation and claims on the front of the package.

${ }^{8} \mathrm{~A}$ reviewer noted that all hypotheses could be couched in terms of the consistency/inconsistency of the claims and the nutrition value information and predictions tested after eliminating the control for the nutrition claim factor and the medium level of nutrition value. Results based on this modified design showed a significant consistency by motivation multivariate interaction and significant univariate results for all dependent variables. There was also a multivariate claim by consistency interaction due only to credibility. The multivariate main effects of claims and nutrition value were significant. For the claim, credibility was the only significant dependent variable in the follow-up univariate tests. Thus, these results were similar to those of the full design, but F-values for this reduced design (no control or medium nutrition level) were stronger than those shown in Table 2. 
ents and/or overall product nutrition perceptions. Significant results between "medium" and "good" conditions, considered in conjunction with prior findings, indicate that differences in cholesterol and sodium are recognized but are not factored strongly into overall nutrition evaluations.

\section{Discussion}

\section{Implications Regarding Nutrition Claims and Nutrition Facts Labels}

One objective of the NLEA was to reduce consumer confusion regarding nutrition information on packages by creating a standardized nutrition label and specifying which package claims could be used under what specific conditions (Pappalardo 1996; Petruccelli 1996; Silverglade 1996). Our experiment addressed consumer product evaluations in this post-NLEA package environment. Drawing from an accessibility/diagnosticity framework and the persuasion knowledge model, hypotheses were offered for the effects of nutrition claims, given the availability of specific nutrition information in the Nutrition Facts panel. In general, our results pertaining to nutrition claims indicate that when a Nutrition Facts panel is readily available, claims do not influence consumers' product-related judgments positively. Claims not consistent with information in the nutrition label resulted in lower evaluations of manufacturer credibility, yet they did not lead to more favorable nutrition and product evaluations compared with a control condition in which no claim was made $\left(\mathrm{H}_{1}\right.$ supported). Similarly, when the claims were consistent with the Nutrition Facts labels, they did not have a significant effect on either specific evaluations of fat content or general nutrition and product evaluations compared to the no-claim control. Also, the claim effects were not influenced by consumers' level of motivation to acquire and process nutrition information ( $\mathrm{H}_{4}$ not supported). Thus, study results suggest that in evaluating the product, consumers rely on the Nutrition Facts panel to a greater extent than they do on nutrition claims on the front of the package.

Our results generally are consistent with the finding of Ford and colleagues (1996) that claims do not affect overall product nutrition beliefs, even though their study used different claims, labels, dependent variables, experimental design, package stimuli, and subject pool (i.e., undergraduate and graduate business students). Taken in conjunction, findings from our study and theirs suggest that consumers do not rely primarily on nutrition claims in making overall nutrition and product evaluations when other nutrition information is readily available. If such results are shown to extend to more realistic in-store purchase settings, this suggests that a less restrictive approach to front package nutrient claims may be preferable if the claim can be verified by information in the Nutrition Facts panel and is presented in a truthful and nonmisleading manner. ${ }^{9}$
However, conclusions regarding the (lack of) influence for claims certainly may not hold for all consumers or all claims that are allowed. Some consumers may lack sufficient desire or ability to process detailed nutrition information and may be influenced significantly by claims on the front of the package. For example, though the claims did not have a significant positive effect on nutrition and product evaluations for the overall sample, a few subjects (approximately 10\%) who received a "low in fat" claim but Nutrition Facts information that indicated that the product was not low in fat appeared to be misled by the claims. Moreover, in one previous in-store shopping experiment, consumers virtually ignored the nutrition panel for cereals unless they were instructed to examine the nutrition information (Cole and Balasubramanian 1992).

In our study, when claims and Nutrition Facts information were not consistent, the "99\% fat free" claim resulted in lower perceptions of credibility than the other nutrition claims. These findings for credibility suggest that some claims (i.e., "low in calories" or "low in fat") may be more vague and difficult to assess for accuracy from the perspective of the consumer (cf. Ford, Smith, and Swasy 1990; Nelson 1974). Although the NLEA regulations have specific nutrient levels required for use of such claims, consumers generally are not aware of these levels or even that regulations for such claims exist (Levy 1995). For nonquantitative claims that are vague (e.g., "low in calories" or "low in fat"), it may become more difficult for consumers to recognize inconsistencies between the claim and the Nutrition Facts data. However, quantitative claims (e.g., "5 grams of fat," "X\% fat free") can be assessed for accuracy more directly from the Nutrition Facts information. Thus, though consumers in FDA focus groups have indicated that the Nutrition Facts panel is a good way to corroborate claims on the front of packages, these results suggest that some claims will be more difficult to verify than others.

In summary, results from this study indicate that when evaluating a food product, consumers tend to rely more on information in the Nutrition Facts panel than on nutrition claims. Thus, in general, consumers seem capable of using information from the Nutrition Facts label for nutrition and product evaluations in the context of a package environment that includes nutrition claims and other information. This bolsters the FDA's contention that most shoppers could be taught to understand the label and (potentially) make use of it in their dietary choices (Burros 1994). Thus, we view these findings as generally supportive of the Nutrition Facts label as it relates to the goal of the NLEA (1990) to "assist consumers in maintaining healthy dietary practices."

These findings for claims and Nutrition Facts labels are consistent with those of recent FDA focus groups in which consumers report that they do not rely solely on claims on the front of packages for nutrition and product evaluations
${ }^{9}$ Such an approach to encourage the provision of salient and truthful information is advocated by the FTC in the regulation of nutrient and health claims in advertising (Federal Trade Commission 1994). In the regulation of nutrient claims on packages, the FDA (1993, pp. 2319-20) has permitted only a limited number of terms (e.g., "low in fat") because it wants to promote consumer understanding of such terms. In contrast, the FTC (1994, p. 12) will examine the overall impression of a wider set of nutrient claims, including synonyms (e.g., "packed with," "lots of"), to determine if consumers are likely to be misled and whether the claims are consistent with FDA definitions. Similarly, whereas the FDA requires triggered disclosures of related nutrients that exceed specified levels when fiber, saturated fat, and cholesterol claims are made, the FTC (1994, p. 15) may require disclosures for nutrient claims when the failure to disclose the presence of other risk-increasing nutrients is likely to be deceptive. 
because they view these claims as a form of promotion used by the manufacturer to help sell the product (Levy 1995). Information from the Nutrition Facts panel, however, is viewed as more credible, and many consumers state that they use it to check the accuracy of claims on the front of the package (cf. Deighton 1984). Thus, results from our study and these FDA focus groups are consistent with predictions based on the persuasion knowledge model and the accessibility/diagnosticity framework.

We believe that these results pertaining to claims raise an intriguing issue. Specific nutrient claims are now restricted by FDA regulations, but FDA focus groups suggest that many consumers are suspicious of claims because they see them as promotion designed to influence purchase behavior. Our findings that show that product attitudes are not affected greatly by claims seem consistent with such reports of suspicion. Taken in sum, these conditions seem to result in a poor environment from a communication perspective; that is, restrictions on substantiated claims may reduce the potential flow of information to consumers, and when such permitted claims are used, consumers appear to question whether the information in the claim should be relied on. Thus, one alternative is to increase the flow of nonmisleading information to consumers. ${ }^{10}$ Also, given the regulation of claims, it seems that consumers could benefit from awareness that there are specific government restrictions on the use of claims on packages. Consumers would have greater confidence in relying on the claims for evaluations yet still have the Nutrition Facts information available for verifying any claims that seem dubious to them. Based on previous arguments that claims do provide significant information value to consumers (Calfee and Pappalardo 1991; Ippolito and Mathios 1991), both consumers and manufacturers may benefit if the manufacturer informs consumers that the product meets the government regulations regarding health and/or nutrition claims that are used on the front of packages.

\section{Implications Regarding Nutritional Motivation of Consumers}

Results indicate that consumers higher in motivation have significantly lower evaluations of "poor" nutrition value products but higher nutrition evaluations of "good" value products compared to consumers lower in motivation $\left(\mathrm{H}_{3}\right.$ supported). Results are particularly strong for the differences in consumer attitudes and purchase intentions between motivation levels when product nutritional value is "poor" (as shown by the comparisons of means in Figure 3 ). We view these findings as having important implications for

${ }^{10}$ For example, if these results generalize to in-store environments, one reviewer suggested that the consumer information environment would be enriched by permitting nutrition and health claims for "better" food products (i.e., those not currently permitted to make an absolute nutrient claim and/or health claims not meeting FDA disqualifying criteria but superior to competitors on relevant nutritional dimensions). As one example (that differs from the FDA's disqualifying level for cholesterol), the FTC Enforcement Policy Statement indicates that "the Commission would not prohibit a truthful advertising claim that explains in a nondeceptive manner the health advantages of substituting meat or poultry items that are relatively low in fat and saturated fat for higher fat alternatives" (Federal Trade Commission 1994, p. 86). consumer welfare. Products in this poor condition were higher in fat, saturated fat, cholesterol, and sodium, nutrients for which higher levels of consumption have been linked to higher risk for diseases such as cancer and coronary heart disease. The fact that the largest differences in product attitudes and purchase intentions occurred for this poor product nutrition condition suggests that low motivation has its greatest effect on perceptions of products most likely to lead to increased risk of diet-related diseases.

The significant difference in overall product attitude and purchase intentions for the least nutritious product for consumers who differ in motivation suggests its relevance to public policy cencerns. The NLEA has specific educational objectives, such as its goals to "educate consumers about (1) the availability of nutrition information in the label and labeling of food, and (2) the importance of that information in maintaining healthy dietary practices" (Nutrition Labeling and Education Act 1990). Efforts to increase consumers' motivation to acquire and process nutrition information are associated closely with such goals, in our opinion. The potential benefits of an increase in motivation are reflected in our results that show large differences in evaluations for products that are poor in nutrition value. If NLEA-based health and productivity benefits are to approach the estimates that range up to $\$ 100$ billion (Pappalardo 1996; Silverglade 1996), efforts to increase both motivation to process and nutrition knowledge must accompany the changes in the package information environment. Further research might address whether there are practical alternatives for increasing the nutrition motivation of the general population.

It was predicted in $\mathrm{H}_{4}$ that claims would have a stronger effect on product evaluations for consumers lower in motivation, because they would rely more on the prominently displayed claims than expend the effort to process the Nutrition Facts panel information. However, all motivation-by-claim interactions were nonsignificant. Consistent with the recent research of Levy (1995) and the persuasion knowledge model, this may suggest that consumers, in general, may be too skeptical of claims to rely solely on them in nutrition and product evaluations, especially when information viewed as more credible and diagnostic is highly accessible.

\section{Importance of Specific Nutrients in Consumer Evaluations}

It has been suggested that many consumers focus almost exclusively on fat content levels in product nutrition evaluations and disregard other elements in the label (e.g., sodium, cholesterol) that also have important health implications (Food and Drug Administration 1993; Food Marketing Institute/Opinion Research Corp. 1992; Food Marketing Institute 1996; Ono 1995). Because a primary objective of the NLEA is to promote healthier dietary practices, the manner in which specific nutrients (linked to health consequences) in the Nutrition Facts label affect consumer evaluations is relevant to assessment of the label. Our results indicate that differences in cholesterol and sodium have little effect on product evaluations, and differences in levels of fat and fat-related nutrients (e.g., calories from fat, saturated fat) have large effects, particularly for consumers with higher motivation. Results for specific nutrients also suggest 
that differences in sodium and cholesterol are recognized, but overall product evaluations do not appear to be affected by perceptions of sodium and cholesterol levels (i.e., little difference in the "medium" and "good" value levels shown in Figures 2 and 3). Although consumers' concern about fat levels is viewed as a positive development, because scientific evidence has shown that sodium and cholesterol are linked to health conditions such as hypertension and heart disease (Food and Drug Administration 1993; Liebman 1995), these results suggest that important information in the Nutrition Facts panel is not factored into consumer product evaluations (cf. Food Marketing Institute 1996).

\section{Limitations and Future Research Concerns}

Several limitations may restrict the generalizability of our findings. Data were collected in a nonstore environment, so that variables such as brand names, promotional displays, time constraints, and other important situational factors that may affect consumers' use of claims and Nutrition Facts information did not influence results. In our study, subjects were encouraged to examine the information on the mock package, and, as noted previously, findings may not extend to retail store or product-use environments. Findings also may not extend beyond the specific levels of the independent variables (i.e., nutrition value and nutrition claims) and the specific dependent variables used in this study. Because a mail survey was used, there was limited researcher control and no opportunity to observe subjects as they used the mock package. Because the study sample was limited to a single state, results may not generalize beyond the population of this particular state. Further research that examines consumers' perceptions and package-related behaviors at the retail point-of-purchase would be particularly useful in extending these findings.

\begin{tabular}{|c|c|c|c|}
\hline Appendix A. & $\mathbf{N u}$ & ition V & alue Co \\
\hline $\begin{array}{l}\text { Serving Size } \\
\text { Servings Per }\end{array}$ & $\begin{array}{l}1 \text { Packa } \\
\text { Containe }\end{array}$ & $e_{1}(280 \mathrm{~g}$ & \\
\hline Amount Per S & erving & & \\
\hline Calories 170 & Calories & om Fat & \\
\hline & & $\% \mathrm{D}$ & ily Value* \\
\hline Total Fat $2 \mathrm{~g}$ & & & $3 \%$ \\
\hline Saturated F & at 0.5 & & $3 \%$ \\
\hline Cholesterol & $20 \mathrm{mg}$ & & $7 \%$ \\
\hline Sodium 410 & $\mathrm{mg}$ & & $17 \%$ \\
\hline Total Carbo & hydrate & $26 \mathrm{~g}$ & $9 \%$ \\
\hline Dietary Fibe & $6 g$ & & $24 \%$ \\
\hline Sugars $6 \mathrm{~g}$ & & & \\
\hline Protein $11 \mathrm{~g}$ & & & \\
\hline Vitamin A $25 \%$ & - & Vitar & in C $15 \%$ \\
\hline Calcium 6\% & • & & Iron $10 \%$ \\
\hline $\begin{array}{l}\text { - Percent Daily V } \\
\text { diet. Your daily } \\
\text { depending on yo }\end{array}$ & $\begin{array}{l}\text { alues are ba } \\
\text { values may b } \\
\text { ur calorie ne }\end{array}$ & $\begin{array}{l}\text { d on a } 2, \\
\text { higher or } \\
\text { ds: }\end{array}$ & $\begin{array}{l}00 \text { calorie } \\
\text { ower }\end{array}$ \\
\hline & Calories: & 2,000 & 2,500 \\
\hline $\begin{array}{l}\text { Total Fat } \\
\text { Saturated Fat } \\
\text { Cholesterol } \\
\text { Sodium } \\
\text { Total Carbohydra } \\
\text { Dietary Fiber } \\
\end{array}$ & $\begin{array}{l}\text { Less than } \\
\text { Less than } \\
\text { Less than } \\
\text { Less than } \\
\text { te }\end{array}$ & $\begin{array}{l}65 \mathrm{~g} \\
20 \mathrm{~g} \\
300 \mathrm{mg} \\
2400 \mathrm{mg} \\
300 \mathrm{~g} \\
25 \mathrm{~g} \\
\end{array}$ & $\begin{array}{l}80 \mathrm{~g} \\
25 \mathrm{~g} \\
300 \mathrm{mg} \\
2400 \mathrm{mg} \\
375 \mathrm{~g} \\
30 \mathrm{~g} \\
\end{array}$ \\
\hline $\begin{array}{l}\text { Calories per gram } \\
\text { Fat } 9\end{array}$ & Carbohydra & 4 & Protein 4 \\
\hline
\end{tabular}

Good

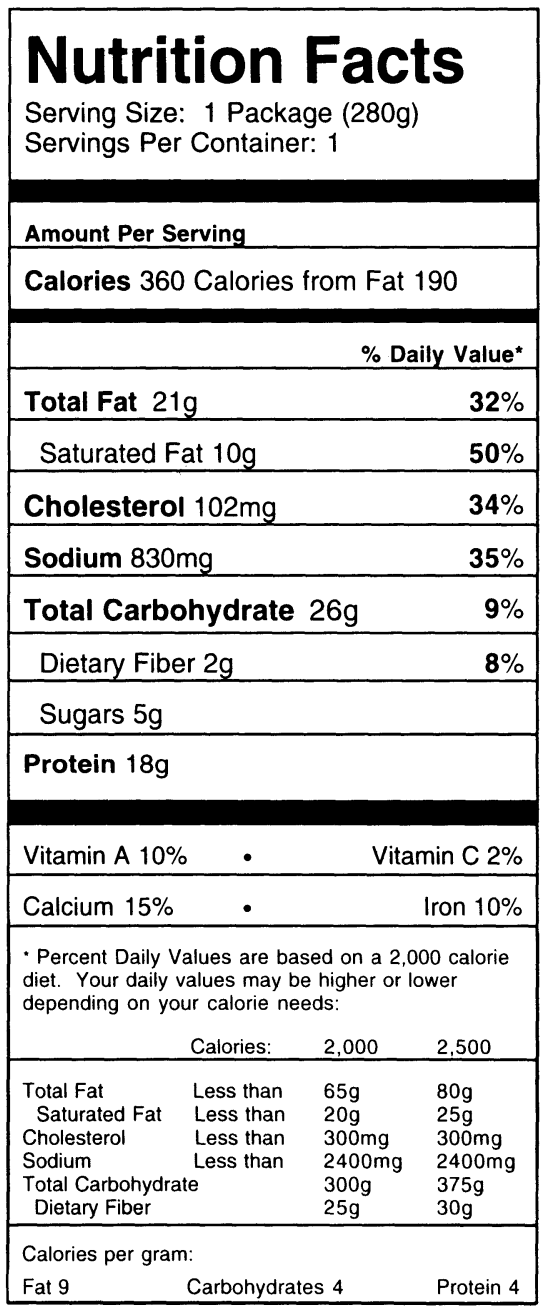

Poor

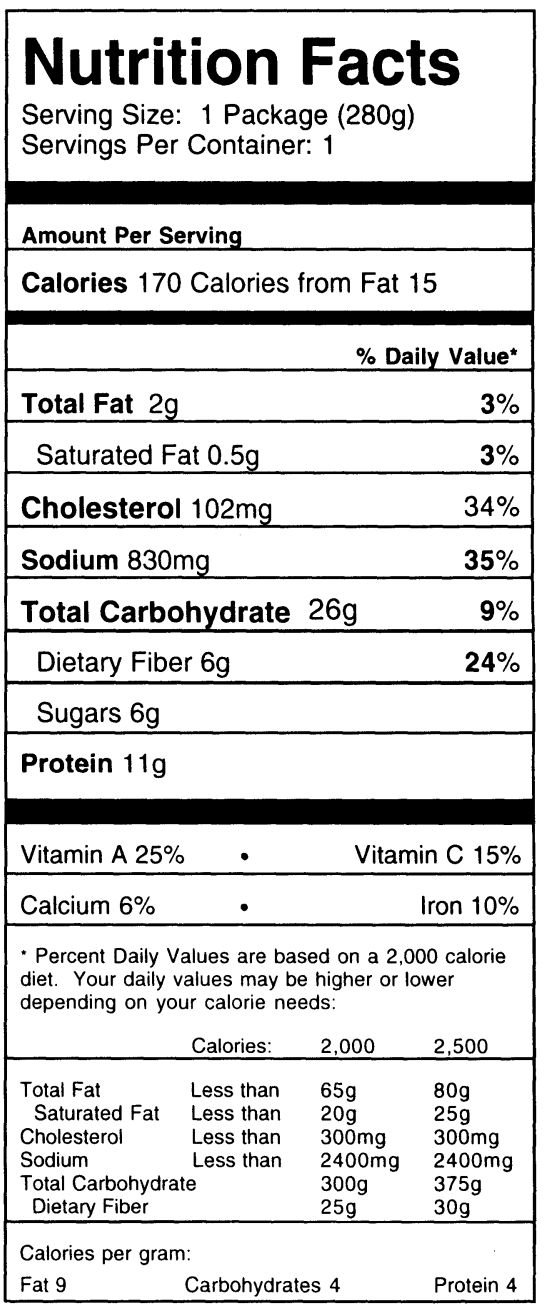

Medium

Note: For the "poor" nutrition value condition, none of the nutrition claims on the front of the package was consistent with the information presented in this Nutrition Facts panel. For the "medium" and "good" nutrition value conditions, each of the package claims was consistent with the nutrition information shown in the panels. 
Results suggest several other possibilities for further research. For example, how consumers acquire and process specific package-related information to arrive at overall nutrition and product evaluations is of interest. If many consumers follow a disjunctive decision strategy in which products are considered acceptable on the basis of levels of fat and fat-related information only, whereas other important nutrients are not factored into evaluations (Food Marketing Institute 1996; Ono 1995), then there are implications for consumer welfare and a need for consumer education. Further research that could address this important issue includes studies employing (1) concurrent protocol methodologies during the product evaluation task, (2) computer-based designs that track which product package and nutrition information is obtained and used by the consumer, and (3) conjoint designs that address the importance of various nutrient and other product package factors in overall evaluations.

Given the results from this study, consideration of the costs and benefits of current nutrition label public health education and/or other promotional measures designed to influence consumer levels of motivation to process nutrition information appears warranted. If further research shows that consumers do not make overly broad generalizations from claims and information on packages, then the package seems to be one way to communicate information about diet-disease relationships supported by scientific evidence and the potential health benefits of dietary practices that may lead to increases in motivation. Research might address the relative effectiveness of different approaches of disseminating information across segments of the population, such as the elderly (Cole and Balasubramanian 1993; Cole and Gaeth 1990) or those with low levels of education, because such segments may show greater benefit than the population at large (Ippolito and Mathios 1991). Also, research may be needed to develop more comprehensive measures of dimensions underlying enduring motivation to process nutrition information and objective nutrition knowledge that could be used to track levels of these variables for representative samples of the population over time (e.g., Levy et al. 1993).

Whereas this study focuses on nutrient content claims and nutrition labels, further research could replicate and extend this work by addressing directly the effects of health claims that are permitted on packages and the "jelly bean" rule (the need for a product to include at least $10 \%$ of the DV of positive nutrients to be defined as "healthy") (e.g., Calfee and Pappalardo 1991; Ford et al. 1996; Ippolito and Mathios 1993; Pappalardo 1996; Silverglade 1996). Also, when a nutrient content claim is made and the food contains other nutrients at a level viewed as potentially increasing the risk of diet-related disease, a triggered disclosure pertaining to the associated nutrient must be made (e.g., for a food high in fiber and high in fat, a high fiber claim requires a disclosure about fat). Findings for sodium and cholesterol in this study suggest that further research address whether "triggered" or required disclosures for high levels of sodium or cholesterol encourage consumers to incorporate such information into product evaluations. Thus, research might address further implications of consumers using fat-related information as the primary cue in evaluations and the effect of triggered disclosures for other nutrients that have important implications for diet-related disease risk.

\section{Appendix B. Dependent Measures ${ }^{a, b}$}

Manufacturer credibility (coefficient $\alpha=.95$ ):

Based on the information provided on the mock package, I believe the food company marketing this food product is: (endpoints of dependable/not dependable [RC]; untrustworthy/trustworthy; credible/not credible $[\mathrm{RC}]$; insincere/sincere; honest/dishonest $[\mathrm{RC}])$.

\section{Nutrition attitude (coefficient $\alpha=.93$ ):}

Based on the information shown on the mock package, what is your overall attitude toward the nutrition content of the product (favorable/unfavorable $[\mathrm{RC}]$ )?

Do you consider the nutrition level offered by the product to be poor/good?

Overall, how would you rate the level of nutritiousness suggested by the information on the package (not nutritious at all/very nutritious)?

Overall attitude toward the product (coefficient $\alpha=.98$ ):

Based on the information shown on the front and back portion of the mock package design, what is your overall attitude toward the product (favorable/unfavorable; good/bad; positive/negative [all $\mathrm{RC}]$ )?

Purchase intention (coefficient $\alpha=.89$ ):

How likely would you be to purchase the product, given the information shown on the front and back of the package (very likely/very unlikely $[\mathrm{RC}])$ ?

Given the information on the front and back of the package, how probable is it that you would consider the purchase of the product (not probable/very probable)?

Would you be more likely or less likely to purchase the product, given the information shown on the package (more likely/less likely $[\mathrm{RC}])$ ?

aAll items were measured using seven-point scales.

b Reverse coding $=\mathrm{RC}$

\section{References}

Alba, Joseph W., J. Wesley Hutchinson, and John Lynch (1991), "Memory and Decision Making," in Handbook of Consumer Behavior, Thomas S. Robertson and Harold H. Kassarjian, eds. Englewood Cliffs, NJ: Prentice-Hall, 1-49.

Anderson, James C. and David W. Gerbing (1988), "Structural Equation Modeling in Practice: A Review and Recommended Two-Step Approach," Psychological Bulletin, 103 (3), 411-23.

Andrews, J. Craig and Terence A. Shimp (1990), "Effects of Involvement, Argument Strength, and Source Characteristics on Central and Peripheral Processing of Advertising," Psychology and Marketing, 7 (Fall), 195-214.

Burros, Marian (1994), "Big Ad Blitz to Introduce Food Labels," The New York Times, (1 May), Section 1, 18.

Burton, Scot and Abhijit Biswas (1993), "A Preliminary Assessment of Changes in Food Labels Required by the Nutritional Labeling and Education Act of 1990," Journal of Consumer Affairs, 27 (Summer), 127-44.

and Richard Netemeyer (1994), "Effects of Alternative Nutrition Label Formats and Nutrition Reference Information on Consumer Perceptions, Comprehension, and Product 
Evaluation," Journal of Public Policy \& Marketing, 13 (Spring), $36-47$.

Calfee, John E. and Janis K. Pappalardo (1991), "Public Policy Issues in Health Claims for Foods," Journal of Public Policy \& Marketing, 10 (Spring), 33-53.

Cole, Catherine A. and Siva K. Balasubramanian (1992), "Individual Differences in Consumers' Willingness to Use Nutritional Information," in Advances in Consumer Research, Vol, 19, John Sherry and Brian Sternthal, eds. Provo, UT: Association for Consumer Research, 489-90. and (1993), "Age Differences in Consumers' Search for Information: Public Policy Implications," Journal of Consumer Research, 20 (June), 157-69.

_ and Gary J. Gaeth (1990), "Cognitive and Age-Related Differences in the Ability to Use Nutritional Information in a Complex Environment," Journal of Marketing Research, 27 (May), 175-84.

Deighton, John (1984), "The Interaction of Advertising and Evidence," Journal of Consumer Research, 11 (December), 763-70.

Federal Trade Commission (1994), Enforcement Policy Statement on Food Advertising. Washington, DC: Federal Trade Commission.

Feldman, Jack M. and John G. Lynch Jr. (1988), "Self-Generated Validity and Other Effects of Measurement on Belief, Attitude, and Behavior," Journal of Applied Psychology, 73 (August), 421-35.

Food and Drug Administration (1993), "Food Labeling Regulations Implementing the Nutrition Labeling and Education Act of 1990," Federal Register, 58 (3), 2066-941.

Food Marketing Institute (1996), Trends in the United States: Consumer Attitudes and the Supermarket, 1996. Washington, DC: Food Marketing Institute

Food Marketing Institute/Opinion Research Corporation (1992), Trends: Consumer Attitudes and the Supermarket, 1992. Washington, DC: Food Marketing Institute.

Food Marketing Institute and Prevention Magazine (1995), Shopping for Health, 1995: New Food Labels, Same Eating Habits? Washington, DC: Food Marketing Institute.

Ford, Gary T., Manoj Hastak, Anusree Mitra, and Debra Jones Ringold (1996), "Can Consumers Interpret Nutrition Information in the Presence of a Health Claim? A Laboratory Investigation," Journal of Public Policy \& Marketing, 15 (Spring), $16-27$.

—, Darlene B. Smith, and John L. Swasy (1990), "Consumer Skepticism of Advertising Claims: Testing of Hypotheses from Economics of Information," Journal of Consumer Research, 16 (March), 433-41.

Fornell, Claes and David F. Larcker (1981), "Evaluating Structural Equation Models with Unobservable Variables and Measurement Error," Journal of Marketing Research, 18 (February), $39-50$.

Friestad, Marian and Peter Wright (1994), "The Persuasion Knowledge Model: How People Cope with Persuasion Attempts," Journal of Consumer Research, 21 (June), 1-31.

Heimbach, James T. and Raymond C. Stokes (1982), "Nutrition Labeling and Public Health: Survey of American Institute of Nutrition Members, Food Industry, and Consumers," American Journal of Clinical Nutrition, 36 (October), 700-708.

Ippolito, Pauline and Alan D. Mathios (1991), "Health Claims in Food Marketing: Evidence on Knowledge and Behavior in the
Cereal Market," Journal of Public Policy \& Marketing, 10 (Spring), 15-32.

and (1993), "New Food Labeling Regulations and the Flow of Nutrition Information to Consumers," Journal of Public Policy \& Marketing, 12 (Fall), 199-205.

Leibman, Bonnie (1995), "One Nation, Under Pressure," Nutrition Action Health Letter, 22 (July/August), 6-9.

Levy, Alan S. (1995), "PHS Food Label Health Claims Focus Group Report: Executive Summary," Food and Drug Administration, Center for Food Safety and Applied Nutrition Division of Market Studies, Washington, DC.

, Sara B. Fein, and Raymond E. Schucker (1991), “A Study of Nutrition Label Formats: Performance and Preference," Food Technology, 45 (July), 116-21.

$\longrightarrow$, $\longrightarrow$, and (1996), "Performance Characteristics of Seven Nutrition Label Formats," Journal of Public Policy \& Marketing, 15 (Spring), 1-15.

- _ - and Marilyn Stephenson (1993), "Nutrition Knowledge Levels About Dietary Fats and Cholesterol: 1983-1988," Journal of Nutrition Education, 25 (3), 60-66.

Moorman, Christine (1990), "The Effects of Stimulus and Consumer Characteristics on the Utilization of Nutrition Information," Journal of Consumer Research, 17 (December), 362-74.

(1996), "A Quasi-Experiment to Assess the Consumer and Informational Determinants of Nutrition Information Processing Activities: The Case of the Nutrition Labeling and Education Act," Journal of Public Policy \& Marketing, 15 (Spring), $28-44$.

$\rightarrow$ Nelson, Phillip (1974), "Advertising as Information," Journal of Political Economy, 83 (July/August), 729-54.

Nutrition Labeling and Education Act (1990), Public Law 101535, 104 Stat. 2355

Ono, Yumiko (1995), "Today's Low-Fat Diet: Pretzels, Licorice," The Wall Street Journal, (14 March), B9.

Pappalardo, Janis K. (1996), "Evaluating the NLEA: Where's the Beef?" Journal of Public Policy \& Marketing, 15 (Spring), 153-55.

Petruccelli, Paul J. (1996), "Consumer and Marketing Implications of Information Provision: The Case of the Nutrition Labeling and Education Act of 1990," Journal of Public Policy \& Marketing, 15 (Spring), 150-53.

Petty, Richard E. and J. T. Cacioppo (1979), "Issue Involvement Can Increase or Decrease Persuasion by Enhancing MessageRelevant Cognitive Responses," Journal of Personality and Social Psychology, 37 (October), 1915-26

and (1986), Communication and Persuasion: Central and Peripheral Routes to Attitude Change. New York: Springer/Verlag.

_, Rao Unnava, and Alan J. Strathman (1991), "Theories of Attitude Change," in Handbook of Consumer Behavior, Thomas S. Robertson and Harold H. Kassarjian, eds. Englewood Cliffs, NJ: Prentice-Hall, 241-80.

Silverglade, Bruce A. (1996), "The Nutrition Labeling and Education Act: Progress to Date and Challenges for the Future," Journal of Public Policy \& Marketing, 15 (Spring), 148-50.

Wright, Peter (1986), "Schemer Schema: Consumers' Intuitive Theories About Marketers' Influence Tactics," in Advances in Consumer Research, Vol. 13, R. Lutz, ed. Provo, UT: Association for Consumer Research, 1-3. 